\title{
The Effect of Maxillary Posterior Space Discrepancy on the Molars and Overbite in Class II Malocclusions with Different Vertical Patterns
}

\author{
Farzaneh Golfeshan ${ }^{1}$, Sepideh Khandadash ${ }^{2}$, Parisa Salehi ${ }^{3}$, Marziye Afsa ${ }^{4}$
}

\begin{abstract}
Aim: The purpose of this cross-sectional study was to investigate the influence of maxillary posterior space discrepancy (MPDD) on angulation and vertical position of molars in patients with skeletal class II malocclusions, presenting long, short, and normal vertical growth patterns.

Materials and methods: In total, 120 lateral cephalograms of patients (mean age: 23 years) with skeletal class II malocclusion were evaluated. Patients were divided into six groups based on their vertical growth pattern (normal, long, and short faces) and the presence or absence of maxillary posterior discrepancy. Maxillary molars'sagittal angulation and vertical position were measured on cephalograms via Dolphin ${ }^{T M}$ threedimensional (3D) software (version 11.5). The comparison between groups with the same vertical dimension and different status of MPDD was done with independent $t$ test. The analysis of analysis (ANOVA) was used to make pairwise comparison between all six groups. Finally, a multiple regression analysis was performed to evaluate the influence of molar position and MPDD on the anterior overbite.

Results: The results showed that the angulation of the maxillary first molar was not statistically different between groups with the same vertical dimension but varied in terms of MPDD. The maxillary second molar was more distally inclined in patients with MPDD than those without MPDD with short and normal facial types ( $p$ value $=0.016$ and $p$ value $=0.001$, respectively). The second molar had significantly more distal angulation in long face patients than short and normal face participants, without considering the status of MPDD. The upper first and second molars were erupted more in patients with long than short or normal faces, without any influence of MPDD.

Conclusion: The presence of MPDD caused more distal inclination of the maxillary second molar, in skeletal class II patients with short and normal vertical growth patterns.

Clinical significance: The status of MPDD and its effect on the maxillary second molar teeth should be considered in skeletal class II patients with short and normal vertical growth patterns.

Keywords: Cephalometry, Molar angulation, Overbite, Posterior space discrepancy.

The Journal of Contemporary Dental Practice (2020): 10.5005/jp-journals-10024-2806
\end{abstract}

\section{INTRODUCTION}

The importance of mesiodistal teeth angulation in orthodontic patients has been emphasized by many clinicians. ${ }^{1-3}$ Molar teeth angulation should be taken into consideration when choosing a treatment plan and mechanotherapy. ${ }^{4}$ The angulation of molar teeth undoubtedly is one of the main determinative factors for anchorage value. Sometimes, by changing the mesiodistal angulation of molar teeth, orthodontists can preserve the anchorage, particularly in class II malocclusions. ${ }^{5-11}$ Diversity and compensatory changes in axial inclination of molars in different malocclusions are the most important factors in anchorage preservation. ${ }^{12-14}$

The angulation of posterior teeth depends on hereditary and gender variables, sequence of teeth eruption, premature exfoliation of primary teeth, extraction of permanent teeth, impacted teeth, posterior space discrepancy (PDD), and different malocclusions. ${ }^{15-17}$

Posterior space discrepancy is considered as deficient available space for third molar eruption in the maxillary and mandibular arch. ${ }^{18-20}$ Since the third molars are the final teeth in eruption sequence, if the space is deficient in posterior part of the arch, they become impacted or semi-impacted. Many theories discuss the effect of PDD on angulation of other teeth in the dental arch. One hypothesis suggests that PDD might increase the mesial angulation of both crown and roots of the first and second molars, ${ }^{21,22}$ while another theory suggests that in such situations, the eruption stress of the third molar tooth produces a mesial movement to the first

\begin{abstract}
1,30rthodontic Research Center, Orthodontic Department, School of Dentistry, Shiraz University of Medical Sciences, Shiraz, Iran

${ }^{2,4}$ School of Dentistry, Shiraz University of Medical Sciences, Shiraz, Iran Corresponding Author: Parisa Salehi, Orthodontic Research Center, Orthodontic Department, School of Dentistry, Shiraz University of Medical Sciences, Shiraz, Iran, Phone: +98 9171110597, e-mail: Salehipa@yahoo.com

How to cite this article: Golfeshan F, Khandadash S, Salehi P, et al. The Effect of Maxillary Posterior Space Discrepancy on the Molars and Overbite in Class II Malocclusions with Different Vertical Patterns. J Contemp Dent Pract 2020;21(4):438-444.
\end{abstract}

Source of support: Nil

Conflict of interest: None

and second molar roots with a simultaneous distal tipping of the crowns. ${ }^{3,10,11,22,23}$ In addition, some studies have mentioned that the presence of PDD might cause super-eruption of the first and second molars, causing open bite malocclusion. ${ }^{24,25}$

Since the incidence of PDD is more common in the lower arch, most of the related studies evaluated the impact of PDD and eruption of the third molar on the angulation of mandibular molar teeth. ${ }^{26-28}$

The aim of this cross-sectional study was to investigate the influence of MPDD on angulation and vertical position of molars in patients with skeletal class II malocclusions, presenting long, short, 
and normal vertical growth patterns. Given the lack of evidence regarding MPDD and its effect on angulation and vertical position of molar teeth in different vertical growth patterns of class II malocclusion, we designed this study. ${ }^{29}$ If there is a strong relationship between the status of MPDD and the angulation and vertical position of molars, it would be wise for the clinician to consider the status of MPDD for decision making in treatment planning.

\section{Materials and Methods}

The Shiraz Dental School Local Ethics Committee (protocol no. 97-01-37-16796) approved this cross-sectional study.

\section{Sample Characteristics}

The samples included pretreatment lateral cephalograms of 120 patients with skeletal class II malocclusion, with minimum age of 23 years. Maximum intercuspation and rest position for the lips were considered while taking all of the cephalograms. Imaging was carried out using an digital panoramic cephalometric equipment (ProMax ${ }^{\oplus}$; Planmeca, Finland) set at $16 \mathrm{~mA}, 72$ kV, and 9.9 seconds. Two calibrated examiners carried out cephalometric analyses digitally via Dolphin ${ }^{\text {TM }} 3 \mathrm{D}$ software (version 11.5). Excluded from the sample were patients with prior orthodontic treatment, cancers, infection, or prosthetic molar reconstruction in the maxillary molar area and without maxillary third molars (extracted or missing) or any other missing/extracted/supernumerary teeth.

For the calculation of sample size, a mean difference of $10^{\circ}$ in the maxillary second molar sagittal inclination was regarded as a clinically relevant discrepancy between groups with and without MPDD. Standard deviation (SD), $\alpha$, and power were set at $4^{\circ}, 0.01$, and $90 \%$, respectively (according to the study of Arriola-Guillén et al.). ${ }^{25}$ Although a minimum of five participants were needed per group, data were used from 120 patients who met the criteria for inclusion.

\section{Sample Grouping}

The cephalograms were classified into six groups based on their present or absent MPDD condition and their vertical patterns of facial growth (normal, long, and short patterns of facial development).

The definitions of the cephalometric measurements used in this study have been shown in Table 1.

All patients presented a skeletal class II malocclusion [A pointNasion-B point (ANB) angle greater than $5^{\circ}$, over jet greater than $4 \mathrm{~mm}$, and molar relationship class II]. The groups were set as follow:

- Group I. Skeletal class II, normal vertical growth pattern with $\operatorname{MPDD}(n=20)$ : Frankfort-Mandibular-angle (FMA) between $25^{\circ} \pm$ 2 , basal plane angle $25^{\circ} \pm 2$, posterior face height to anterior face height (PFH/AFH) 62 to $65 \%$, overbite 1 to $2 \mathrm{~mm}, \mathrm{~A}^{\prime} 6 / \mathrm{A}^{\prime} \mathrm{P}>$ 46\% (25) (Fig. 1).

- Group II. Skeletal class II, normal vertical growth pattern without $\operatorname{MPDD}(n=20)$ : FMA angle between $25^{\circ} \pm 2$, basal plane angle $25^{\circ} \pm 2, \mathrm{PFH} / \mathrm{AFH} 62$ to $65 \%$, overbite 1 to $2 \mathrm{~mm}, \mathrm{~A}^{\prime} 6 / \mathrm{A}^{\prime} \mathrm{P}<46 \%$.

- Group III. Skeletal class II, long face growth pattern with MPDD $(n=20)$ : FMA angle $\geq 27$, basal plane angle $\geq 27, \mathrm{PFH} / \mathrm{AFH} \leq 62 \%$, overbite $\leq 1 \mathrm{~mm}, \mathrm{~A}^{\prime} 6 / \mathrm{A}^{\prime} \mathrm{P}>46 \%$.

- Group IV. Skeletal class II, long face growth pattern without MPDD $(n=20):$ FMA angle $\geq 27$, basal plane angle $\geq 27$, PFH/ $\mathrm{AFH} \leq 62 \%$, overbite $\leq 1 \mathrm{~mm}, \mathrm{~A}^{\prime} 6 / \mathrm{A}^{\prime} \mathrm{P}<46 \%$.

- Group V. Skeletal class II, short face growth pattern with MPDD $(n=20)$ : FMA angle $\leq 23$, basal plane angle $\leq 23, \mathrm{PFH} / \mathrm{AFH} \geq$ $67 \%$, overbite $\geq 3 \mathrm{~mm}, A^{\prime} 6 / \mathrm{A}^{\prime} \mathrm{P}>46 \%$.
Table 1: The definitions of the cephalometric points, distances, and angles

\begin{tabular}{ll}
\hline Variables & Definition \\
\hline SNA & $\begin{array}{l}\text { The angle between points sella (S), nasion } \\
(\mathrm{N}) \text {, and subnasal }(\mathrm{A}) \text { in degrees }\end{array}$ \\
SNB & $\begin{array}{l}\text { The angle between points sella (S), nasion } \\
(\mathrm{N}), \text { and supra mental (B) in degrees }\end{array}$ \\
ANB & $\begin{array}{l}\text { The angle between subnasal (A), nasion (N), } \\
\text { and supra mental (B) in degrees } \\
\text { Overbite }\end{array}$ \\
& $\begin{array}{l}\text { The distance between incisal edge of } \\
\text { maxillary and mandibular central incisor, } \\
\text { perpendicular to occlusal plane, in } \\
\text { millimeters }\end{array}$
\end{tabular}

FMA The angle between the porion-orbital line and mandibular plane in degrees

Basal angle The angle between mandibular and palatal plane in degrees

$\mathrm{PFH} \quad$ The linear distance from sella to the inferior border of the mandible, generally the gonion, in millimeters

AFH The linear distance from the nasion to the bottom of the chin, the menton point, in millimeters

PFH/AFH The posterior facial height divided by anterior facial height

Upper first molar-PP The angle formed by the maxillary first molar axis (intercuspid groove-bifurcation) and the palatal plane (ANS-PNS) in degrees (Fig. 2)

Upper second The angle formed by the maxillary second molar-PP molar axis (intercuspid groove-bifurcation) and the palatal plane (ANS-PNS) in degrees (Fig. 2)

$\mathrm{A}^{\prime} \mathrm{P}^{\prime}$ (maxillary base The distance between the perpendicular length) extensions of points $A$ and $P$ on the palatal plane $\left(A^{\prime} P^{\prime}\right)$ in millimeters: point $A^{\prime}$ is the perpendicular projection of point $A$ to the palatal plane and point $\mathrm{P}^{\prime}$ is the perpendicular projection of the posteriormost point of the maxillary tuberosity to the palatal plane (Fig. 1)

$\mathrm{A}^{\prime} 6^{\prime}$ (anterior maxillary base length)

The distance between $\mathrm{A}^{\prime}$ and $6^{\prime}$ in millimeters. Point $\sigma^{\prime}$ is the perpendicular projection of the anterior-most point on the proximal surface of the maxillary first molar to the palatal plane (Fig. 1)

Ratio $\left(A^{\prime} \sigma^{\prime} / A^{\prime} P^{\prime}\right) \quad$ The ratio of the anterior maxillary base length $A^{\prime} \sigma^{\prime}$ to the maxillary base length $A^{\prime} P^{\prime}$ $\left(A^{\prime} 6^{\prime} / A^{\prime} P^{\prime}\right)$

Upper first molar's The perpendicular distance between palatal vertical position plane and maxillary first molar, measured from cusp tip, in millimeters (Fig. 3)

Upper second mo- The perpendicular distance between palatal lar's vertical position plane and maxillary second molar, measured from cusp tip, in millimeters (Fig. 3)

- Group VI. Skeletal class II, short face growth pattern without $\operatorname{MPDD}(n=20)$ : FMA angle $\leq 23$, basal plane angle $\leq 23$, PFH/ $A F H \geq 67 \%$, overbite $\geq 3 \mathrm{~mm}, \mathrm{~A}^{\prime} 6 / \mathrm{A}^{\prime} \mathrm{P}<46 \%$.

\section{Maxillary Posterior Space Discrepancy}

The possible eruption blockage of the maxillary third molar is known as a maxillary posterior discrepancy due to the presence of erupted second molar during clinical examination. 


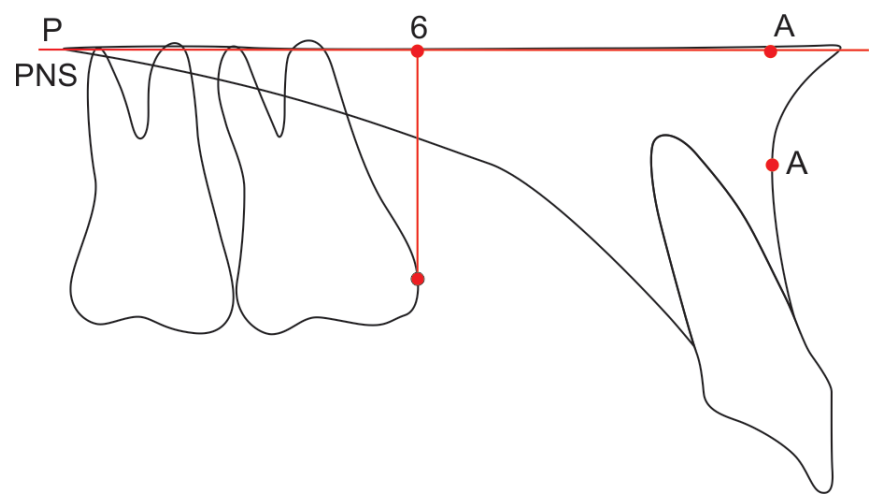

Fig. 1: Maxillary posterior discrepancy determination

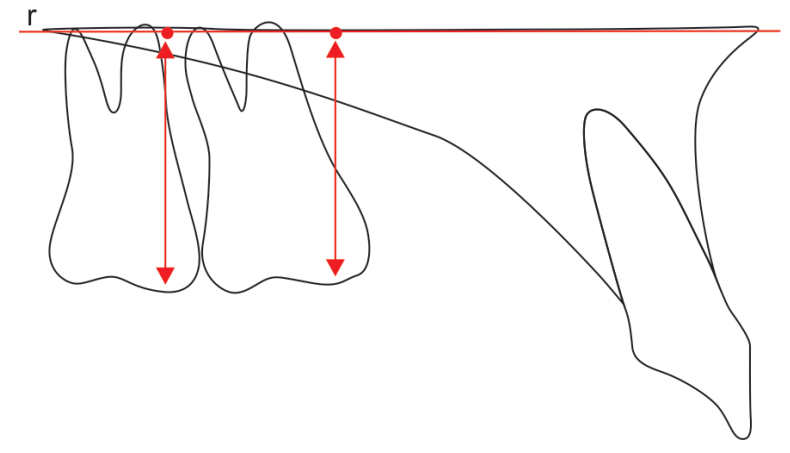

Fig. 3: Maxillary molar vertical position

For statistical analysis, an additional analysis of maxillary posterior difference was considered in our research based on cephalometric measurements. If the ratio of anterior maxillary base length $\left(A^{\prime} \sigma^{\prime}\right)$ to maxillary base length $\left(A^{\prime} P^{\prime}\right)$ exceeds 0.46 , a maxillary posterior discrepancy has been determined ${ }^{25}$ (Fig. 1).

\section{Maxillary Molar Sagittal Angulation}

The sagittal angulations of the first and second maxillary molars are determined by the angle created by the molar axis and the palatal plane (Fig. 2).

\section{Maxillary Molar Vertical Position}

The vertical position of the maxillary molars was measured by calculating the perpendicular distances between the palatal plane to the maxillary first and second molar mesial cusp tips (Fig. 3).

\section{Statistical Analysis}

The data were analyzed using SPSS version 22 (IBM SPSS, Chicago, IL, USA). Using Shapiro-Wilk measures, normality was tested. To determine the differences between two groups identified by MPDD, an independent $t$ test was performed. All groups were compared using ANOVA, and if a significant difference was observed, post hoc Tuckey was used. To assess the effect of maxillary molar sagittal and vertical location on the overbite as a dependent variable, a multiple linear regression analysis was performed.

\section{Results}

All of the cephalometric measurements were evaluated within a 1-month interval, by two independent examiners. An intra-class correlation coefficient (ICC) has been used to test the accuracy of

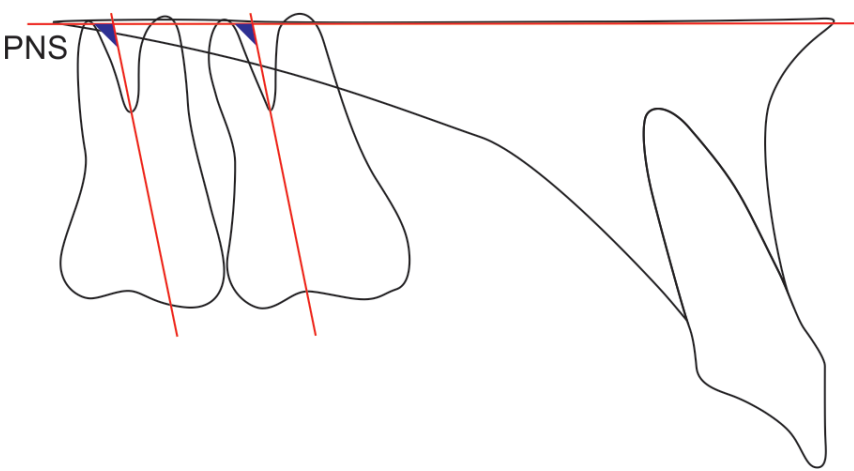

Fig. 2: Maxillary molar sagittal angulation

Table 2: The descriptive statistics of all sample groups

\begin{tabular}{|c|c|c|c|c|}
\hline \multirow{2}{*}{\multicolumn{2}{|c|}{ Groups }} & \multicolumn{2}{|c|}{$n(\operatorname{sex})$} & \multirow{2}{*}{$\frac{\text { Age }}{\text { Mean } \pm S D}$} \\
\hline & & n female & n male & \\
\hline 1 & Normal MPDD+ & 11 & 9 & $22.22 \pm 1.59$ \\
\hline 2 & Normal MPDD- & 8 & 12 & $22.48 \pm 1.61$ \\
\hline 3 & Vertical MPDD+ & 10 & 10 & $24.20 \pm 0.69$ \\
\hline 4 & Vertical MPDD- & 12 & 8 & $24.22 \pm 1.13$ \\
\hline 5 & Horizontal MPDD+ & 7 & 13 & $24.87 \pm 1.66$ \\
\hline 6 & Horizontal MPDD- & 10 & 10 & $24.90 \pm 1.75$ \\
\hline
\end{tabular}

inter- and intra-examiner. All values reached 0.90 [95\% confidence interval (Cl) 0.87-0.98].

The descriptive statistics of all sample groups are presented in Table 2. Table 3 shows the results of independent $t$ test between groups according to the presence or absence of MPDD. The results showed that the angulation of the first maxillary molar did not differ statistically between groups with the same vertical dimension but differed in terms of MPDD. The maxillary second molars were more distally inclined in patients with MPDD than those without MPDD in short and normal facial types. The vertical position of upper first molar and upper second molar was not influenced by the presence or absence of MPDD.

The results of ANOVA test are presented in Table 4. All the principal variables (maxillary molar sagittal angulation and vertical position) were compared in six groups and pairwise. The upper first molar's sagittal angulation was not statistically different between groups. The upper second molar had significantly more distal angulation in long face patients than short and normal face participants (Fig. 4). The eruption of the upper first and second molars was more in patients with long face, in comparison with the short or normal face patients (Fig. 5).

The multiple linear regression analysis is presented in Table 5. The results showed that as a dependent factor, none of the variables had a significant effect on predicting overbite.

\section{Discussion}

Different theories regarding MPDD and its effect on the sagittal and vertical positions of molar teeth in different malocclusions exist. In one theory, it was assumed that in patients with PDD, the pressure from the eruption of the maxillary third molars with PDD made the first and second molar teeth more mesially angulated and over erupted. ${ }^{21,22,24,25}$ The advocate of this theory linked this condition to increased bite opening and vertical growth pattern. 
Table 3: The descriptive statics and result of independent $t$ test between groups according to the presence or absence of PDD

\begin{tabular}{|c|c|c|c|c|c|}
\hline Measurement & Group & Mean $\pm S D$ & Group & Mean $\pm S D$ & $p$ value \\
\hline ANB & \multirow[t]{12}{*}{ Normal+ } & $8.5 \pm 1.2$ & \multirow[t]{12}{*}{ Normal- } & $7.4 \pm 2.2$ & 0.60 \\
\hline FMA & & $24.3 \pm 2.2$ & & $25.3 \pm 1.1$ & 0.53 \\
\hline Basal angle & & $25.4 \pm 2.3$ & & $26.5 \pm 2.5$ & 1 \\
\hline Facial height index & & $64.5 \pm 1.3$ & & $64.8 \pm 1.2$ & 0.98 \\
\hline Overbite & & $2.3 \pm 1.1$ & & $2.7 \pm 1.9$ & 0.90 \\
\hline$A^{\prime} \sigma^{\prime}$ & & $28.1 \pm 3.4$ & & $22.2 \pm 4.5$ & $<0.001^{*}$ \\
\hline $\mathrm{A}^{\prime} \mathrm{P}^{\prime}$ & & $54.6 \pm 4.3$ & & $54.3 \pm 4.6$ & 0.79 \\
\hline$A^{\prime} \sigma^{\prime} / A^{\prime} P^{\prime}$ & & $51.2 \pm 1.9$ & & $39.2 \pm 4.2$ & $<0.001^{*}$ \\
\hline Upper first molar/PP & & $85.6 \pm 7.3$ & & $84.7 \pm 3.4$ & 0.13 \\
\hline Upper second molar/PP & & $79.7 \pm 6.3$ & & $85.3 \pm 5.9$ & $<0.001^{*}$ \\
\hline Upper first molar V & & $23.3 \pm 4.5$ & & $23.9 \pm 5.7$ & 0.26 \\
\hline Upper second molar V & & $20.9 \pm 4.4$ & & $21.3 \pm 2.2$ & 0.11 \\
\hline ANB & \multirow[t]{12}{*}{ Long+ } & $7.5 \pm 1.2$ & \multirow[t]{12}{*}{ Long- } & $8.1 \pm 4.4$ & 0.68 \\
\hline FMA & & $35.3 \pm 3.5$ & & $36.4 \pm 2.2$ & 0.51 \\
\hline Basal angle & & $29.5 \pm 4.4$ & & $30.2 \pm 1.4$ & 0.91 \\
\hline Facial height index & & $54.3 \pm 3.2$ & & $53.6 \pm 3.6$ & \\
\hline Overbite & & $-3.4 \pm(-1.3)$ & & $-3.5 \pm(-2.1)$ & 0.77 \\
\hline$A^{\prime} 6^{\prime}$ & & $26.4 \pm 2.4$ & & $21.4 \pm 3.2$ & $<0.001^{*}$ \\
\hline$A^{\prime} P^{\prime}$ & & $51.9 \pm 4.6$ & & $52.3 \pm 4.7$ & 0.40 \\
\hline$A^{\prime} \sigma^{\prime} / A^{\prime} P^{\prime}$ & & $55.9 \pm 5.2$ & & $40.6 \pm 6.8$ & $<0.001^{*}$ \\
\hline Upper first molar/PP & & $79.2 \pm 6.8$ & & $81.5 \pm 4.7$ & 0.41 \\
\hline Upper second molar/PP & & $74.5 \pm 5.7$ & & $75.4 \pm 6.4$ & 0.75 \\
\hline Upper first molar V & & $26.5 \pm 2.2$ & & $25.9 \pm 2.6$ & 0.76 \\
\hline Upper second molar V & & $25.3 \pm 3.6$ & & $25.2 \pm 2.9$ & 0.94 \\
\hline ANB & \multirow[t]{12}{*}{ Short+ } & $7.4 \pm 5.4$ & \multirow[t]{12}{*}{ Short- } & $8.2 \pm 3.2$ & 0.78 \\
\hline FMA & & $18.4 \pm 2.3$ & & $19.4 \pm 3.9$ & 0.08 \\
\hline Basal angle & & $20.2 \pm 2.1$ & & $19.5 \pm 4.4$ & 0.31 \\
\hline Facial height index & & $78.4 \pm 4.8$ & & $80.2 \pm 6.4$ & 0.93 \\
\hline Overbite & & $6.4 \pm 2.2$ & & $5.8 \pm 2.1$ & 0.52 \\
\hline$A^{\prime} 6^{\prime}$ & & $17.6 \pm 4.5$ & & $23.2 \pm 1.1$ & $<0.001^{*}$ \\
\hline$A^{\prime} P^{\prime}$ & & $53.5 \pm 3.5$ & & $54.7 \pm 2.3$ & 0.44 \\
\hline$A^{\prime} \sigma^{\prime} / A^{\prime} P^{\prime}$ & & $51.6 \pm 4.7$ & & $35.9 \pm 2.4$ & $<0.001^{*}$ \\
\hline Upper first molar/PP & & $87.6 \pm 7.5$ & & $85.3 \pm 6.9$ & 0.50 \\
\hline Upper second molar/PP & & $86.5 \pm 4.7$ & & $89.6 \pm 5.6$ & 0.016 \\
\hline Upper first molar V & & $22.3 \pm 2.7$ & & $21.3 \pm 2.8$ & 0.75 \\
\hline Upper second molar V & & $19.3 \pm 2.9$ & & $19.7 \pm 3.7$ & 0.65 \\
\hline
\end{tabular}

${ }^{*} p$ values $<0.05$ were considered as significant

Table 4: The results of ANOVA test

\begin{tabular}{lccll}
\hline & U6/PP & U7/PP & $\begin{array}{l}\text { U6 vertical } \\
\text { position }\end{array}$ & $\begin{array}{l}\text { U7vertical } \\
\text { position }\end{array}$ \\
\cline { 2 - 5 } Group & Mean $\pm S D$ & Mean $\pm S D$ & Mean $\pm S D$ & Mean $\pm S D$ \\
\hline Normal+ & $85.6 \pm 7.3^{\mathrm{a}}$ & $79.7 \pm 6.3^{\mathrm{a}}$ & $23.3 \pm 4.5^{\mathrm{a}}$ & $20.9 \pm 4.4^{\mathrm{a}}$ \\
Normal- & $84.7 \pm 3.4^{\mathrm{a}}$ & $85.3 \pm 5.9^{\mathrm{b}}$ & $23.9 \pm 5.7^{\mathrm{a}}$ & $21.3 \pm 2.2^{\mathrm{a}}$ \\
Long+ & $79.2 \pm 6.8^{\mathrm{a}}$ & $74.5 \pm 5.7^{\mathrm{c}}$ & $26.5 \pm 2.2^{\mathrm{b}}$ & $25.3 \pm 3.6^{\mathrm{b}}$ \\
Long- & $81.5 \pm 4.7^{\mathrm{a}}$ & $75.4 \pm 6.4^{\mathrm{c}}$ & $25.9 \pm 2.6^{\mathrm{b}}$ & $25.2 \pm 2.9^{\mathrm{b}}$ \\
Short+ & $87.6 \pm 7.5^{\mathrm{a}}$ & $86.5 \pm 4.7^{\mathrm{b}}$ & $22.3 \pm 2.7^{\mathrm{a}}$ & $19.3 \pm 2.9^{\mathrm{a}}$ \\
Short- & $85.3 \pm 6.9^{\mathrm{a}}$ & $89.6 \pm 5.6^{\mathrm{d}}$ & $21.3 \pm 2.8^{\mathrm{a}}$ & $19.7 \pm 3.7^{\mathrm{a}}$ \\
\hline
\end{tabular}

Each two numbers with one common letter in each column is not significantly different
Based on this theory, their recommendation was to extract the third molars in cases with PDD to prevent crowding in anterior segments of dental arch.

In another theory, it was mentioned that the eruption force from the third molars in the presence of PDD forced the roots of molar teeth mesially, and as a result, the crown became distally. ${ }^{23}$ None of the mentioned theories are supported by sufficient scientific evidence.

Considering the clinical importance of this issue, especially in class II patients, in this study, we evaluated the effect of PDD on angulation and vertical position of molar teeth in skeletal class II patients with different vertical growth patterns.

We have discussed the outcome of this study in three parts for more clarification. 


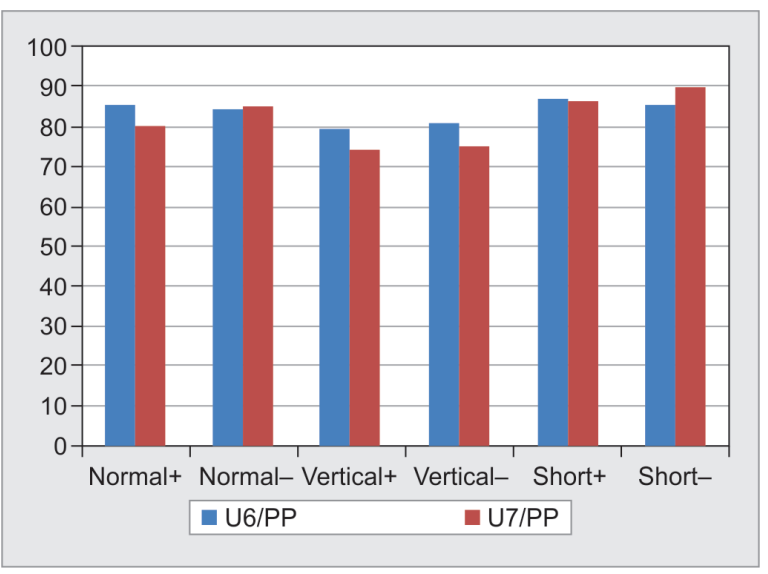

Fig. 4: Comparison of inclination of the maxillary first and second molars in different groups

Part 1: The effect of PDD on sagittal angulation and vertical position of the maxillary molars in class II patients with different vertical growth patterns.

Part 2: Sagittal angulation and vertical position of the maxillary molars in skeletal class II patients with different vertical growth patterns, without considering the presence or absence of MPDD.

Part 3: The effect of mesiodistal and vertical positions of the maxillary molars on the overbite as a dependent variable.

\section{Part 1}

The results of this study showed that the presence of MPDD had no effect on the mesiodistal angulation of the first molar in all three types of facial growth patterns. In patients with short and normal facial growth patterns, MPDD caused more distal crown tipping of the second molar teeth in comparison with patients without MPDD, while in long face patients, MPDD had no effect on sagittal angulation of the second molar teeth.

In our study, the first molar teeth did not have influence on MPDD in all types of malocclusions. In most of the recent studies, ${ }^{25-27}$ these teeth had a similar behavior to the second molar teeth but in smaller magnitude. Different age groups or different methods of cephamometric measurements used may be responsible for this difference.

$\mathrm{Kim}^{26}$ and $\mathrm{Sato}^{27}$ in their hypothesis mentioned that the presence of MPDD or the pressure from erupting the maxillary third molar teeth causes more mesial crown inclination of the first and second molar teeth. They correlate this mesial inclination with posterior teeth interference and concurrent bite opening. As we mentioned, in our study, not only MPDD did not influence on molar sagittal angulation in long face subjects but also caused distal crown angulation in short and normal subjects. This result was in support of the second hypothesis that the stress from the maxillary third molars on the anterior molar teeth will produce mesial root displacements and distal crown angulation. ${ }^{25,28-31}$ In addition, it seems that in long face subjects as we discussed later, some other factors than MPDD influenced molar sagittal angulation.

The results are clinically relevant as the clinician will take these factors into account when meeting patients with possible MPDD. In patients with skeletal class II and short face pattern, distalization of posterior teeth is the main mechanotherapy. ${ }^{32}$ As the second molars were more distally inclined in patients with MPDD, the distal force applied from orthodontic appliance may place these teeth in

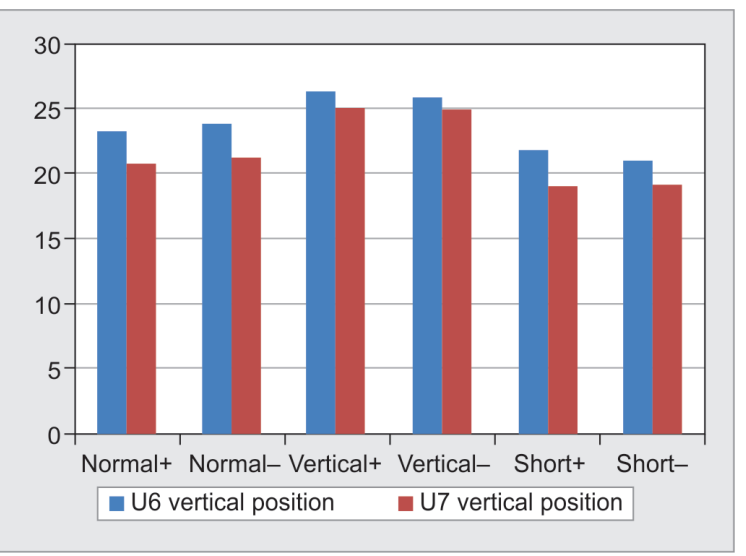

Fig. 5: Comparison of vertical position of the maxillary first and second molars in different groups

unstable positions, and as a sequence, the stability of the treatment becomes questionable.

In this study, the MPDD did not have influence on the vertical dimension of molar teeth in all types of malocclusions. The existence of MPDD was suggested to produce second and first molars extrusion. This could lead to a reduction in overbite. ${ }^{24,33,34}$ The expected results based on this theory are that in the groups with positive MPDD, the vertical dimension of molar teeth becomes increased. But we did not find such a relationship. It seemed that the vertical positions of molars are more influenced by some other factors such as types of growth patterns and mandibular plane inclination than the presence or absence of MPDD.

\section{Part 2}

There are some contradictory results regarding the sagittal and vertical positions of molars in different malocclusions. Some studies $^{35-37}$ expressed that the only factor that can predict the angulation of molar teeth is the sagittal malocclusions. As in class II malocclusions, the molar teeth are more distally inclined than normal malocclusions. Compensatory angulation of upper molars to occlude with more distally positioned lower molars is the main reason to support their theory. Because our samples consisted of only class II patients, we cannot compare our results between different sagittal malocclusions.

Su et al. ${ }^{30}$ compared the mesiodistal angulation of the first molar in different malocclusions. They concluded that in the skeletal class II patients with long face growth pattern, the angulation of the upper first molar was more distally inclined and in skeletal class II patients with short face growth pattern, the angulation was more mesially inclined. In the study by Liao et al. ${ }^{38}$ and Chang and Moon, ${ }^{31}$ long face patients had more distally tipped maxillary first molar.

As previously mentioned, in our study, the angulation of the upper first molar was not statistically different between groups. May be the possible impact of MPDD is not so strong to have an effect on the first molar teeth that locate more far from the third molar teeth than the second molar. The upper second molar teeth were more distally inclined in long face groups than normal and short face groups. This is probably due to their distally angled eruption path. It may also occur in the long face group due to more divergent palatal and mandibular planes; the molars must have a greater distal angulation to occlude. ${ }^{39}$

The clinical importance of these results is in the skeletal class II patients with long face pattern. Sometimes, the treatment 
Table 5: The multiple linear regression analysis $\left(R=0.998, R^{2}=0.995\right.$, adjusted $R=0.97, F=55.16, p$ value $\left.=0.101\right)$

\begin{tabular}{lcccccc}
\hline & \multicolumn{3}{c}{$\begin{array}{c}\text { Unstandardized } \\
\text { coefficients }\end{array}$} & Standardized & & \\
\cline { 2 - 6 }$n=120$ & $B$ & $S E$ & coefficient beta & $p$ value & $95 \% \mathrm{Cl}$ \\
\hline Intercept & 74.40 & 54.17 & & 0.401 & -613.96 & 762.77 \\
Upper first molar/PP & -0.457 & 0.403 & -0.28 & 0.46 & -5.58 & 4.66 \\
Upper second molar/PP & 0.221 & 0.155 & 0.275 & 0.390 & -1.750 & 2.191 \\
Upper first molar/V & -1.502 & 0.73 & -0.606 & 0.282 & -10.55 & 7.55 \\
Upper second molar/V & -0.731 & 0.805 & -0.388 & 0.531 & 10.94 & 9.50 \\
\hline
\end{tabular}

$\mathrm{SE}$, standard error

plan in these patients is to extract premolars and space closure. Using straight archwire with conventional buccal tubes should be considered more carefully in these cases. As these tubes have mesially angulated slots, the mesial moments produced with $\mathrm{NiTi}$ archwires caused the molar teeth to occupy the extraction space and consequently resulting in loss of anchorage.

In comparison between groups with different growth patterns, patients with long face pattern had more erupted upper first and second molars compared with normal and short face patients. The results confirm previous observation. ${ }^{39-41}$ From a clinical point of view, controlling the vertical position of these teeth or in some cases intruding them should be considered in long face patients.

\section{Part 3}

The regression analysis showed that none of our principal variables (vertical and mesiodistal positions of the maxillary molar teeth) had an effect on overbite as a dependent factor. It could be concluded that upper molars' angulation and vertical positions are not the principal factors in controlling overbite. Similar results were found in the previous studies..$^{25,29,42}$ It seems that compensatory eruption of the anterior teeth is one of the reasons that make overbite independent from our principal variables.

The major limitation of this study was its retrospective design. It was not possible to evaluate the influence of MPDD on the results of the treatment and its stability. Further studies with larger sample sizes and different sagittal and vertical malocclusions should be performed prospectively to evaluate the influence of MPDD on the result and stability of the orthodontic treatment, more precisely.

\section{CONCLUSION}

The mesiodistal angulation of the maxillary first molar and vertical position of the maxillary first and second molars were not significantly different comparing group I (normal with MPDD) with group II (normal without MPDD), group III (long face with MPDD) with group IV (long face without MPDD), and, finally, group C (short face with MPDD) with group VI (short face without MPDD). The maxillary second molar had more distal inclination in group I (normal with MPDD) and group V (short face with MPDD) in comparison with group II (normal without MPDD) and group VI (short face without MPDD), respectively. In addition, the maxillary first and second molars were more erupted in groups III and IV (long face with MPDD and without MPDD) than the other four groups. The mesiodistal and vertical positions of the maxillary first and second molars did not have any significant effect on anterior overbite in all of the six groups.

\section{ACKNOWLEDgments}

Authors wish to thank Mr H. Argasi at the Research Consultation Center (RCC) of Shiraz University of Medical Sciences for his invaluable assistance in editing this manuscript.

\section{References}

1. Balut N, Klapper L, Sandrik J, et al. Variations in bracket placement in the preadjusted orthodontic appliance. Am J Orthod Dentofacial Orthop 1992;102(1):62-67. DOI: 10.1016/0889-5406(92)70015-3.

2. Miethke R. Third order tooth movements with straight wire appliances. Influence of vestibular tooth crown morphology in the vertical plane. J Orofac Orthop 1997;58(4):186-197. DOI: 10.1007/ BF02679959.

3. Miethke RR, Melsen B. Effect of variation in tooth morphology and bracket position on first and third order correction with preadjusted appliances. Am J Orthod Dentofacial Orthop 1999;116(3):329-335. DOI: 10.1016/S0889-5406(99)70246-5.

4. Fayad JB, Levy JC, YazbeckC, et al. Eruption of third molars: relationship to inclination of adjacent molars. Am J Orthod Dentofacial Orthop 2004;125(2):200-202. DOI: 10.1016/j.ajodo.2003.10.010.

5. Londhe S, Kumar P, Mitra R, et al. Efficacy of second molar to achieve anchorage control in maximum anchorage cases. Med J Armed Forces India 2010;66(3):220-224. DOI: 10.1016/S0377-1237(10)80041-3.

6. M'Lissa MR, Sadowsky C. Efficacy of intraarch mechanics using differential moments for achieving anchorage control in extraction cases. Am J Orthod Dentofacial Orthop 1997;112(4):441-448. DOI: 10.1016/S0889-5406(97)70053-2.

7. Hart A, Taft L, Greenberg SN. The effectiveness of differential moments in establishing and maintaining anchorage. Am J Orthod Dentofacial Orthop 1992;102(5):434-442. DOI: 10.1016/S08895406(05)81190-4.

8. Upadhyay M, Yadav S, Nagaraj K, et al. Treatment effects of miniimplants for en-masse retraction of anterior teeth in bialveolar dental protrusion patients: a randomized controlled trial. Am Orthod Dentofacial Orthop 2008;134(1):18.e1-29.e1. DOI: 10.1016/ j.ajodo.2007.03.025.

9. Lai EH-H, Yao C-CJ, Chang JZ-C, et al. Three-dimensional dental model analysis of treatment outcomes for protrusive maxillary dentition: comparison of headgear, miniscrew, and miniplate skeletal anchorage. Am J Orthod Dentofacial Orthop 2008;134(5):636-645. DOI: 10.1016/j.ajodo.2007.05.017.

10. Hilgers JJ. The pendulum appliance for class II non-compliance therapy. J Clin Orthod 1992;26(11):706-714.

11. Nanda RS, Dandajena TC. The role of the headgear in growth modification. Semin Orthod 2006;12(1):25-33. DOI: 10.1053/ j.sodo.2005.10.006.

12. Bondemark L, Kurol J. Class II correction with magnets and superelastic coils followed by straight-wire mechanotherapy. J Orofac Orthop 1998;59(3):127-138. DOI: 10.1007/BF01317174.

13. ByloffFK, DarendelilerMA.Distal molar movement using the pendulum appliance. Part 1: clinical and radiological evaluation. Angle Orthod 
1997;67(4):249-260. DOI: 10.1043/0003-3219(1997)067<0249:DMMU $\mathrm{TP}>2.3 . \mathrm{CO} ; 2$.

14. Geron S, Shpack N, Kandos S, et al. Anchorage loss-a multifactorial response. Angle Orthod 2003;73(6):730-737. DOI: 10.1043/0003-3219(2003)073<0730:ALMR>2.0.CO;2.

15. Vela E, Taylor RW, Campbell PM, et al. Differences in craniofacial and dental characteristics of adolescent Mexican Americans and European Americans. Am J Orthod Dentofacial Orthop 2011;140(6):839-847. DOI: 10.1016/j.ajodo.2011.04.026.

16. Årtun J, Thalib L, Little RM. Third molar angulation during and after treatment of adolescent orthodontic patients. Eur J Orthod 2005;27(6):590-596. DOI: 10.1093/ejo/cji049.

17. Swessi $D$, Stephens $C$. The spontaneous effects of lower first premolar extraction on the mesio-distal angulation of adjacent teeth and the relationship of this to extraction space closure in the long term. Eur J Orthod 1993;15(6):503-511. DOI: 10.1093/ejo/15.6.503.

18. Rijpstra C, Lisson JA. Etiology of anterior open bite: a review. J Orofac Orthop 2016;77(4):281-286. DOI: 10.1007/s00056-016-0029-1.

19. Behbehani F, Årtun J, Thalib L. Prediction of mandibular thirdmolar impaction in adolescent orthodontic patients. Am J Orthod Dentofacial Orthop 2006;130(1):47-55. DOI: 10.1016/ j.ajodo.2006.03.002.

20. Årtun J, Behbehani F, Thalib L. Prediction of maxillary third molar impaction in adolescent orthodontic patients. Angle Orthod 2005;75(6):904-911. DOI: 10.1043/0003-3219(2005)75[904:pomtmi]2 $.0 . \mathrm{co} ; 2$.

21. Merrifield LL, Klontz HA, Vaden JL. Differential diagnostic analysis system. Am J Orthod Dentofacial Orthop 1994;106(6):641-648. DOI: 10.1016/S0889-5406(94)70090-7.

22. Kim YH, Han UK, Lim DD, et al. Stability of anterior openbite correction with multiloop edgewise archwire therapy: a cephalometric follow-up study. Am J Orthod Dentofacial Orthop 2000;118(1):43-54. DOI: $10.1067 /$ mod.2000.104830.

23. Costa MGd, Pazzini CA, Pantuzo MCG, et al. Is there justification for prophylactic extraction of third molars? A systematic review. Braz Oral Res 2013;27(2):183-188. DOI: 10.1590/S1806-83242013000100024.

24. Tanaka EM, Sato S. Longitudinal alteration of the occlusal plane and development of different dentoskeletal frames during growth. Am J Orthod Dentofacial Orthop 2008;134(5):602.e1-602.e11 10.1016/ j.ajodo.2008.07.010.

25. Arriola-Guillén LE, Aliaga-Del Castillo A, Pérez-Vargas LF, et al. Influence of maxillary posterior discrepancy on upper molar vertical position and facial vertical dimensions in subjects with or without skeletal open bite. Eur J Orthod 2015;38(3):251-258. DOI: 10.1093/ejo/ cjv067.

26. Kim YH. Anterior openbite and its treatment with multiloop edgewise archwire. Angle Orthod 1987;57(4):290-321. DOI: 10.1043/0003-3219(1987)057<0290:AOAITW>2.0.CO;2.
27. Sato S. An approach to the treatment of malocclusion in consideration of dentofacial dynamics. Tokyo: Torin Books; 1991.

28. Badawi Fayad J, Levy JC, Yazbeck C, et al. Eruption of third molars: relationship to inclination of adjacent molars. Am J Orthod Dentofacial Orthop 2004;125(2):200-202. DOI: 10.1016/j.ajodo.2003.10.010.

29. Arriola-Guillén LE, Aliaga-Del Castillo A, Flores-Mir C. Influence of maxillary posterior dentoalveolar discrepancy on angulation of maxillary molars in individuals with skeletal open bite. Prog Orthod 2016;17(1):34. DOI: 10.1186/s40510-016-0147-8.

30. Su H, Han B, Li S, et al. Compensation trends of the angulation of first molars: retrospective study of 1403 malocclusion cases. Int J Oral Sci 2014;6(3):175-181. DOI: 10.1038/ijos.2014.15.

31. Chang YI, Moon SC. Cephalometric evaluation of the anterior open bite treatment. Am J Orthod Dentofacial Orthop 1999;115(1):29-38. DOI: 10.1016/S0889-5406(99)70313-6.

32. Gandhi V, Mehta F, Parekh $\mathrm{H}$, et al. A new appliance for efficient molar distalization. J Clin Orthod 2017;51(11):738-747.

33. Ribeiro GL, Regis Jr S, da Cunha TD, et al. Multiloop edgewise archwire in the treatment of a patient with an anterior open bite and a long face. Am J Orthod Dentofacial Orthop 2010;138(1):89-95. DOI: 10.1016/j.ajodo.2008.03.036.

34. Sato S, Takamoto K, Suzuki Y. Posterior discrepancy and development of skeletal class III malocclusion: its importance in orthodontic correction of skeletal class III malocclusion. Orthod Rev 1988;2(6):16-29.

35. Ruiz-Mora GA, Arriola-Guillen LE, Flores-Mir C. Maxillary first molar vertical and horizontal position based on sagittal and vertical facial skeletal growth patterns on CBCT-synthesized cephalograms of adult patients with different dentofacial discrepancies but with normal overbite. Oral Health Dent Manage 2014;13(4):1152-1157. DOI: 10.4172/2247-2452.1000746.

36. Henry RG. A classification of class II, division I malocclusion. Angle Orthod 1957;27(2):83-92.

37. Chen S, Du FY, Chen G, et al. Enhancement of molar anchorage with X buccal tube. Chin J Orthod 2013;20(1):26-30.

38. Liao C, Yang P, Zhao Z, et al. Study on the posterior teeth mesiodistal tipping degree of normal occlusion subjects among different facial growth patterns. Hua Xi Kou Qiang Yi Xue Za Zhi 2010;28(4):374-377.

39. Björk A. Prediction of mandibular growth rotation. Am J Orthod 1969;55(6):585-599. DOI: 10.1016/0002-9416(69)90036-0.

40. Cangialosi TJ. Skeletal morphologic features of anterior open bite. Am J Orthod 1984;85(1):28-36. DOI: 10.1016/0002-9416(84)90120-9.

41. Enlow DH, Kuroda $T A$, Lewis AB. Intrinsic craniofacial compensations. Angle Orthod 1971;41(4):271-285. DOI: 10.1043/ 0003-3219(1971)041<0271:ICC>2.0.CO;2.

42. Aliaga-Del Castillo A, Janson G, Arriola-Guillén LE, et al. Effect of posterior space discrepancy and third molar angulation on anterior overbite. Am J Orthod Dentofacial Orthop 2018;154(4):477-486. DOI: 10.1016/j.ajodo.2017.12.014. 